\title{
Fresh Outlook to Understanding Maternal Stress in NICUs
}

Chantal Lau, PhD

The increased survival of preterm infants in neonatal intensive care units (NICUs) over the last decades has heightened our awareness of the stress encountered by their mothers. Unfortunately, no well-defined intervention protocols are yet available to assist these parents during such unfortunate times (1-7). This likely ensues from our limited understanding of the challenges these mothers face in tandem with the concern over their child(ren) 's fragility, particularly their temperament and/or hardships in their personal life (8). Indeed, perception of stressfulness is not only a result of a recipient's traits, e.g., resilience, coping abilities (9) but also of their environment. These elements together determine the response intensity of an individual to a particular prolonged stressful situation.

\section{"This brief aims to share with neonatal/ perinatal practitioners the greater in- depth understanding we recently gained regarding the complex "assortment" of stressors that mothers face simultaneously during their infant's NICU hospitalization (10). As mothers are not the patients, it is understandable that NICU providers do not necessarily know how best to support them."}

This brief aims to share with neonatal/perinatal practitioners the greater in-depth understanding we recently gained regarding the complex "assortment" of stressors that mothers face simultaneously during their infant's NICU hospitalization (10). As mothers are not the patients, it is understandable that NICU providers do not necessarily know how best to support them. However, the latter's concerns over their well-being should not be undervalued as the integrity of a mother-infant dyad is crucial for her infant's proper development and growth (s). The customary concerns expressed by NICU staff, e.g., physicians, nurses, lactation consultants, are primarily directed towards maternal depression and anxiety, e.g., reasons for infrequent visits and/or breastfeeding/ pumping. However, our recent study highlights the complexity of how the interactions of all the stressors facing mothers at the same time may be the actual culprits that prevent us from offering these parents better support during their baby(ies)' NICU hospitalization. A brief description of our study (10) is presented herein to propose a more rational reason as to why mothers' attitudes do not always meet our expectations.

In nature, ecologists have long recognized how the multitude of stressors simultaneously impacting an organism within its natural ecosystem could lead to uncertain developmental or behavioral outcomes. The latter is not only a result of the impact of the individual stressors but rather of the complex multitude of potential synergistic/antagonistic interactions occurring among them. Consequently, foretelling any conceivable outcome(s) becomes difficult (11-13). Animals respond in a similar manner to their environment. Although it is common to study the individual effects of stressors in animals, their combined effects have not received the attention they deserve (13). Based on the similarities existing between organisms under stress in our natural world and our NICU mothers, it was deemed of value to examine whether the MultipleStressor modeling approach well recognized in Ecology may assist in the development of similar maternal mediational models during their infants' NICU hospitalization. With the ability to identify maternal traits by their NICU experiences through self-reported psychological tests, it was hypothesized that the Multiple-Stressor theoretical framework might allow for the development of similar mediational models of maternal stress. If achievable, neonatal care providers would gain a better "grasp" of the varied stressors most impactful to these parents' respective attributes and socioeconomic environment.

\section{" it was hypothesized that the Multiple- Stressor theoretical framework might allow for the development of similar mediational models of maternal stress. If achievable, neonatal care providers would gain a better "grasp" of the varied stressors most impactful to these parents' respective attributes and socioeconomic environment."}

In this recent study, 30 mothers of infants born between 24- and 29-week gestation were recruited. Table 1 shows the self-reported psychological tests used to evaluate subjects' characteristics and stress responses to the NICU. Two focused on personal characteristics/traits, i.e., the magnitude of a responder's emotional responses to stress [Affect Intensity Measure (AIM)] and his/her truthfulness when responding to self-reported testing [Social Desirability Scale (CM)]. Five tests monitored their stress responses to anxiety (BSI-Anx), coping skills under stressful situations (CISS), postpartum depression (EDPS), perceived social support (MSPSS), and parental stress scale in the NICU (PSS:NICU). Table 2 presents subjects' responses by ethnicity/race. Self-reported testing was conducted at two weeks postpartum once their infants were deemed clinically stable. One-way ANOVA and post hoc Fisher LSD analyses were used to compare subjects' characteristics and stress responses between ethnic/racial groups. Significant differences between groups were only observed between 
Table 1 - Self-reported Traits \& Stress Responses

\begin{tabular}{|c|c|}
\hline Traits & To evaluate \\
\hline $\begin{array}{l}\text { Affect Intensity Measure (AIM) } \\
\text { \{Larsen, } 1987 \# 9877\}\end{array}$ & $\begin{array}{l}\text { - } \frac{\text { trait characterizing an individual's magnitude of emotional }}{\text { response }} \\
\text { (the higher the score, the greater the emotional response) }\end{array}$ \\
\hline $\begin{array}{l}\text { Crowne-Marlowe Social Desirability Scale (CM) } \\
\text { \{Crowne, } 1960 \# 7929\}\end{array}$ & $\begin{array}{l}\text { - } \text { trait characterizing an individual's } \\
\text { - inclination to be viewed favorably by others } \\
\text { - truthfulness of responses } \\
\text { (the lower the score, the more truthful the response) }\end{array}$ \\
\hline \multicolumn{2}{|l|}{ Stress Responses } \\
\hline $\begin{array}{l}\text { Anxiety (Brief Symptom Inventory) (BSI-Anx) } \\
\text { \{Derogatis, \#12552\} }\end{array}$ & - anxiety \\
\hline $\begin{array}{l}\text { Edinburgh Postnatal Depression Scale (EPDS) } \\
\text { \{Cox, } 1987 \# 7745\}\end{array}$ & $\begin{array}{l}\text { - postpartum depression } \\
\text { (the higher the score, the greater the depression }\end{array}$ \\
\hline $\begin{array}{l}\text { Multidimensional Scale of Perceived Social Suppport (MSPSS) } \\
\text { \{Zimet, } 1988 \# 8208\}\end{array}$ & $\begin{array}{l}\text { - perceived social support } \\
\text { (the higher the score, the greater the perceived social support) }\end{array}$ \\
\hline $\begin{array}{l}\text { Parental Stress Scale:NICU (PSS:NICU) } \\
\text { \{Miles, } 1993 \# 3737\}\end{array}$ & $\begin{array}{l}\text { - perceived stress in the NICU from: } \\
\text { - sights \& sounds in NICU (S\&S) } \\
\text { - baby's looks/behaviors (Looks) } \\
\text { - parental role alteration (Parent) } \\
\text { - staff communication (Staff) } \\
\text { (the higher the scores, the more stressful these factors) }\end{array}$ \\
\hline
\end{tabular}

education, income, and subjects' social desirability trait. No significant difference was noted between ethnicity/race in maternal responses to self-reported tests that monitored anxiety, coping skills through the use of avoidance-, emotion-, and/or task-oriented behaviors, depression, perceived social support or lack thereof, and PSS:NICU stress.

Insofar as our interest was to identify maternal characteristics and stressors that may be implicated in the maternal self-reported stress responses monitored (Table 2), multiple regression analyses were first conducted to identify maternal attributes significantly associated $(p \leq 0.05)$ with individual stress outcomes for all mothers. Following this, the Multiple-Stressor approach was evaluated using the "Best Subset Regression" analysis (www.minitab. com). This statistical method compares "best-fitting models" as determined by ranking all the subsets of significant maternal attributes or predictors identified in order of highest to lowest adjusted $\mathrm{R}^{2}$ values (https://support.minitab.com/en-us/minitab-express/1/ help-and-how-to/modeling-statistics/regression/how-to/best-subsets/before-you-start/overview/). Our study focused only on the four factors that best contributed, i.e., highest p-values, to each of the ten stress outcomes monitored (Table 3 ). The latter shows how mothers' responses to the varied mediational stress models were associated with different combinations of maternal attributes that had differing positive (synergistic) or negative (antagonistic) correlations depending on the stress outcomes monitored [NB: not all of the four factors identified within each model necessarily were of statistical significance $(p \leq 0.05)]$.

\section{"In brief, our recent study (10) validated the applicability of the Multiple-Stressor framework to clinical studies, offering a means to appreciate better the intricate struggle confronting NICU mothers."}

In support of the Multiple-Stressor theoretical framework, these data show how changes in a specific maternal attribute can lead to a series of "chain reactions" impacting other stress outcomes through interactions between them. For instance, at a first 
Table 2. Maternal Characteristics, Traits, \& Stress Responses by Ethnicity/Race

\begin{tabular}{|c|c|c|c|c|}
\hline \multicolumn{5}{|c|}{ Maternal Characteristics/Traits } \\
\hline & Caucasian & $\begin{array}{l}\text { African- } \\
\text { American }\end{array}$ & Hispanic & $\mathrm{p}^{* *}$ \\
\hline Number & 13 & 8 & 9 & \\
\hline Maternal age & $31.6 \pm 6.5^{*}$ & $26.8 \pm 6.6$ & $26.4 \pm 6.8$ & 0.128 \\
\hline Education & $6.6 \pm 1.4^{\mathrm{a}}$ & $6.2 \pm 1.5^{b}$ & $4.4 \pm 1.6^{\mathrm{a}, \mathrm{b}}$ & 0.001 \\
\hline Income & $3.3 \pm 0.6^{\mathrm{a}, \mathrm{b}}$ & $2.0 \pm 0.8^{a}$ & $1.9 \pm 1.0^{b}$ & $<0.001$ \\
\hline Infant's gestational age (wks) & $27.8 \pm 1.5$ & $26.5 \pm 1.4$ & $26.4 \pm 2.0$ & 0.131 \\
\hline Infant's birth weight (g) & $1044 \pm 233$ & $821 \pm 145$ & $970 \pm 210$ & 0.070 \\
\hline Maternal health" & $1.3 \pm 1.5$ & $1.4 \pm 0.5$ & $0.8 \pm 0.4$ & 0.520 \\
\hline Affect Intensity Measure (AIM) & $3.6 \pm 0.4$ & $3.8 \pm 0.6$ & $3.9 \pm 0.5$ & 0.465 \\
\hline Social Desirability Scale (CM) & $16.5 \pm 5.8^{\mathrm{ab}}$ & $26.4 \pm 4.2^{\mathrm{a}}$ & $22.3 \pm 4.2^{b}$ & 0.001 \\
\hline \multicolumn{5}{|c|}{ Self-Reported Stress Responses } \\
\hline Anxiety (BSI-Anx) & $57.3 \pm 12.3$ & $52.9 \pm 8.4$ & $48.9 \pm 11.5$ & 0.297 \\
\hline $\begin{array}{l}\text { Coping Skills (CISS) } \\
\text { - Use of Task-oriented behavior }\end{array}$ & $49.7 \pm 15.1$ & $56.0 \pm 8.6$ & $45.0 \pm 10.8$ & 0.273 \\
\hline - Use of Emotion-oriented behavior & $48.0 \pm 9.4$ & $47.4 \pm 11.1$ & $48.5 \pm 12.2$ & 0.980 \\
\hline - Use of Avoidance-oriented behavior & $46.5 \pm 11.4^{\mathrm{a}}$ & $59.4 \pm 12.5^{\mathrm{a}}$ & $47.8 \pm 10.8$ & 0.060 \\
\hline Depression (EPDS) & $10.9 \pm 4.7$ & $11.6 \pm 6.2$ & $13.5 \pm 5.5$ & 0.546 \\
\hline Perceived Social Support (MSPSS) & $6.5 \pm 0.5$ & $5.5 \pm 1.3$ & $6.2 \pm 0.9$ & 0.084 \\
\hline $\begin{array}{l}\text { Parental Stress Scale (PSS:NICU) } \\
\text { - NICU Sight \& Sound }\end{array}$ & $3.1 \pm 0.7$ & $2.5 \pm 1.2$ & $2.3 \pm 1.3$ & 0.268 \\
\hline - Baby's Looks & $3.4 \pm 0.7$ & $2.9 \pm 1.2$ & $3.3 \pm 1.1$ & 0.479 \\
\hline - Parenting Role & $4.3 \pm 0.9$ & $4.1 \pm 1.1$ & $3.9 \pm 1.2$ & 0.736 \\
\hline - Staff Communication & $2.2 \pm 1.0$ & $1.5 \pm 0.6$ & $1.7 \pm 0.9$ & 0.252 \\
\hline
\end{tabular}

* Mean \pm SD $\quad * * 1$ way ANOVA a,b post hoc Fisher LSD: $p<0.05$ between symbols

\# Number of postpartum visits to a healthcare provider

\begin{tabular}{|c|c|c|c|c|c|c|c|c|}
\hline Codes & 1 & 2 & 3 & 4 & 5 & 6 & 7 & 8 \\
\hline Education & $<6^{\text {th }}$ grade & $6^{\text {th }}$ & $8^{\text {th }}$ & $10^{\text {th }}$ & $12^{\text {th }}$ & $14^{\text {th }}$ & $16^{\text {th }}$ & $<16$ th \\
\hline Income & $<\$ 10,000$ & $\begin{array}{c}\$ 10,000- \\
49,999\end{array}$ & $\begin{array}{c}\$ 50,000- \\
99,999\end{array}$ & $\begin{array}{c}\geq \\
\$ 100,000\end{array}$ & & & & \\
& & 49, & & & \\
\hline
\end{tabular}


Table 3. Mediational models of the 4 factors contributing best to each Stress Outcome

\begin{tabular}{|c|c|c|c|c|}
\hline \multirow{2}{*}{$\begin{array}{l}\text { Stress Outcomes } \\
\text { Anxiety (BSI-Anx) }\end{array}$} & \multicolumn{4}{|c|}{ Combined 4 factors/predictors contributing best to each Stress Outcomes } \\
\hline & Income $(+)^{\#}(<0.001)^{\S}$ & CISS-Task (-\# (0.001) & CISS-Avoidance(+) (0.004) & $\operatorname{AIM}(-)(0.021)$ \\
\hline $\begin{array}{l}\text { CISS } \\
\text { - Task-oriented }\end{array}$ & Education $(+)(0.002)$ & BSI-Anx (-) (0.002) & MSPSS (+) (0.010) & CISS-Avoidance (+) (0.026) \\
\hline - Emotion-oriented & $\operatorname{EPDS}(+)(\mathbf{0 . 0 0 1})$ & CM (-) (0.024) & Looks (-) (0.062) & $\operatorname{AIM}(+)(0.369)$ \\
\hline - Avoidance-oriented & Income $(-)(<0.001)$ & $\operatorname{AIM}(+)(<0.001)$ & CISS-Task $(+)(<0.001)$ & BSI-Anx (+) (0.004) \\
\hline Depression (EPDS) & $\begin{array}{l}\text { Parent Role Alteration }(+) \\
\qquad(<0.001)\end{array}$ & CISS-Emotion (+) (0.001) & Race (0.002) & MSPSS (-) (0.006) \\
\hline MSPSS & $\mathrm{CM}(-)(<0.001)$ & CISS-Emotion (-) (0.008) & CISS-Task (+) (0.032) & $\operatorname{AIM}(+)(0.092)$ \\
\hline $\begin{array}{l}\text { PSS:NICU } \\
\text { - Sights \& Sounds }\end{array}$ & Baby's Looks (+) (0.012) & CM (-) (0.020) & Education $(+)(\mathbf{0 . 0 2 8})$ & AIM (+) (0.049) \\
\hline - Baby's Looks & $\begin{array}{l}\text { Parental Role Alteration }(+) \\
\qquad(<\mathbf{0 . 0 0 1 )}\end{array}$ & Income $(+)(0.006)$ & Race (0.008) & CISS-Emotion (-) (0.121) \\
\hline - Parental Role Alteration & Baby's Looks $(+)(<0.001)$ & Race (0.002) & $\operatorname{EPDS}(+)(\mathbf{0 . 0 0 3})$ & BSI-Anx (-) (0.386) \\
\hline - Staff Communication & EPDS $(+)(0.020)$ & Income $(+)(0.075)$ & CISS-Emotion (-) (0.088) & Sights \&Sounds (+) (0.197) \\
\hline
\end{tabular}

(+) positive and (-) negative correlation with Stress Outcomes

$\S$

$p$ value for individual factor/predictor within each mediational model (significance at $p \leq 0.05$ )

level, Depression can be impacted by Parental Role Alteration (PSS:NICU), CISS-Emotion, and MSPSS [Table 3]. At a secondary level, Parental Role Alteration, in turn, would lead to an altered Parental Perception of Baby's looks (PSS:NICU) while CISSEmotion and MSPSS affect responders' truthfulness (CM) in their response to their self-reported tests. At a third level, MSPSS may additionally affect the respondents' CISS-Task.

\section{"In conclusion, our observations support the use of the Multiple-Stressor mediational modeling in human studies. This novel approach offers a more comprehensive understanding of the complex psychosocial environment NICU mothers face than currently available."}

In brief, our recent study (10) validated the applicability of the Multiple-Stressor framework to clinical studies, offering a means to appreciate better the intricate struggle confronting NICU mothers. It illustrates how such an analytical approach can assist in identifying not only the maternal attributes at risk but, importantly, their interactive "networking" pathways in affecting overall maternal well-being. With a clearer understanding of the impact that maternal attributes can have on differing stress outcomes, it is advanced that such an approach can facilitate the development of more efficient and integrated intervention protocols to assist NICU mothers. However, caution is raised towards the truthfulness of subjects' responses to self-reported tests, as we have already observed in earlier studies $(8,14)$.

In summary, the following observations are advanced: 1. the different interactions existing between maternal characteristics and their self-reported stress responses validate the use of the Multiple-Stressor framework for human studies; 2 . the ability to identify the most stressful outcomes early on in babies' NICU stay will "facilitate early targeted guidance and social support to help mothers develop more constructive parenting ....and positive mutualistic parenting routine for themselves and their babies" (8); 3 . identification of the synergistic or antagonistic impact of these attributes onto individual stress outcomes would facilitate psychosocial therapists in offering more focused and relevant approach(es) to better support these mothers; 4. the "chain reaction/networking" pathways taken by individual attributes may better guide therapeutic approaches; 5 . this approach can help identify the impacts that factors unique to each parent, e.g., education, income, race, AIM, can have on maternal stress outcomes.

In conclusion, our observations support the use of the Multiple-Stressor mediational modeling in human studies. This novel approach offers a more comprehensive understanding of the complex psychosocial environment NICU mothers face than currently available.

\section{References:}

1. Sabnis A, Fojo S, Nayak SS, Lopez E, Tarn DM, Zeltzer L. Reducing parental trauma and stress in neonatal intensive care: systematic review and meta-analysis of hospital interventions. J Perinatol. 2019;39(3):375-386.

2. Roque ATF, Lasiuk GC, Radünz V, Hegadoren K. Scoping 
Review of the Mental Health of Parents of Infants in the NICU. J Obstet Gynecol Neonatal Nurs. 2017;46(4):576-587.

3. O'Brien K, Robson K, Bracht M, et al. Effectiveness of Family Integrated Care in neonatal intensive care units on infant and parent outcomes: a multicentre, multinational, clusterrandomised controlled trial. The Lancet Child \& adolescent health. 2018;2(4):245-254.

4. Haward MF, Lantos J, Janvier A. Helping Parents Cope in the NICU. Pediatrics. 2020;145(6).

5. Chertok IR, McCrone S, Parker D, Leslie N. Review of interventions to reduce stress among mothers of infants in the NICU. Advances in neonatal care : official journal of the National Association of Neonatal Nurses. 2014;14(1):30-37.

6. Treyvaud K, Spittle A, Anderson PJ, O'Brien K. A multilayered approach is needed in the NICU to support parents after the preterm birth of their infant. Early Hum Dev. 2019;139:104838.

7. Franck LS, O'Brien $K$. The evolution of family-centered care: From supporting parent-delivered interventions to a model of family integrated care. Birth defects research. 2019;111(15):1044-1059.

8. Lau C, Turcich MR, Smith EO. Early detection of parenting stress in mothers of preterm infants during their first-year home. BMC psychology. 2020;8(1):66.

9. Lecic-Tosevski D, Vukovic O, Stepanovic J. Stress and personality. Psychiatrike = Psychiatriki. 2011;22(4):290-297.

10. Lau C, Turcich MR, Fraley JK. Mediational models of maternal stress in neonatal intensive care units. Pediatric Medicine. 2021.

11. Maher RL, Rice MM, McMinds R, Burkepile DE, Vega Thurber R. Multiple stressors interact primarily through antagonism to drive changes in the coral microbiome. Scientific reports. 2019;9(1):6834.

12. Piggott JJ, Townsend CR, Matthaei CD. Reconceptualizing synergism and antagonism among multiple stressors. Ecol Evol. 2015;5(7):1538-1547.

13. Hale R, Piggott JJ, Swearer SE. Describing and understanding behavioral responses to multiple stressors and multiple stimuli. Ecol Evol. 2017;7(1):38-47.

14. Lau C, Hurst NM, Smith EO, Schanler RJ. Ethnic/racial diversity, maternal stress, lactation and very low birthweight infants. J Perinatol. 2007;27(7):399-408.

Disclosures: The author has no disclosures.

NT

Corresponding Author:
Chantal Lau PhD
Adjunct Associate Professor
Department of Pediatrics
Baylor College of Medicine
Houston, TX, USA
Email:clau@bcm.edu

\section{Keeping Your Baby Sate}

during the COVID-19 pandemic

\section{How to protect your little one from germs and viruses}

Even though there are some things we don't know about COVID-19 yet. there are many more things that we do know. We know that there are proven protective measures that we can take to stay healthy.

\section{Here's what you can do...}
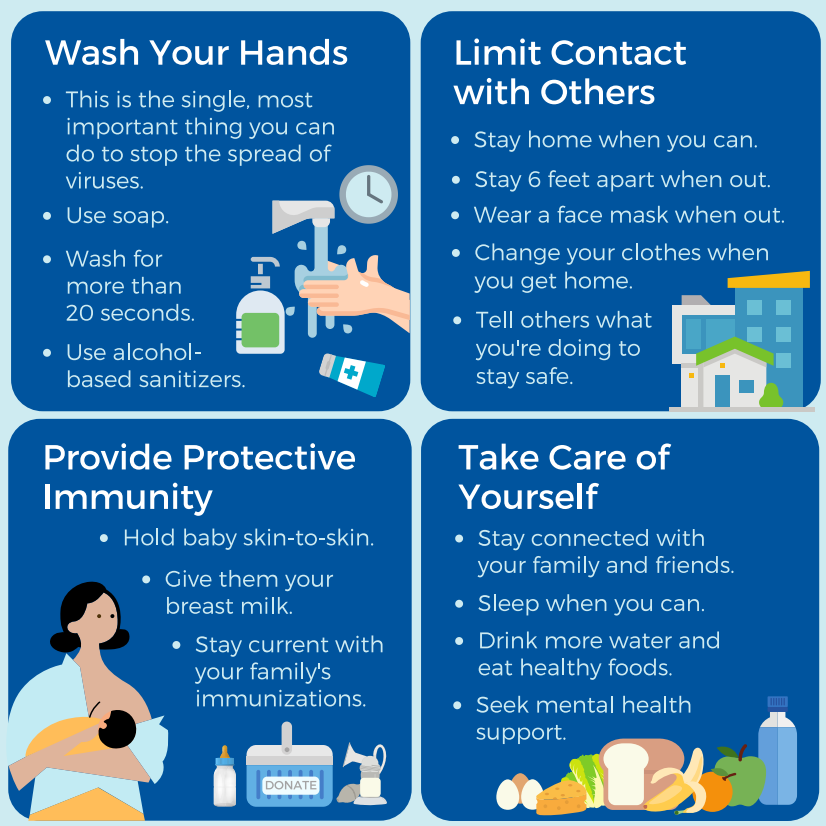

Immunizations Vaccinations save lives. Protecting your baby from flu and pertussis lowers their risks for complications from coronavirus.
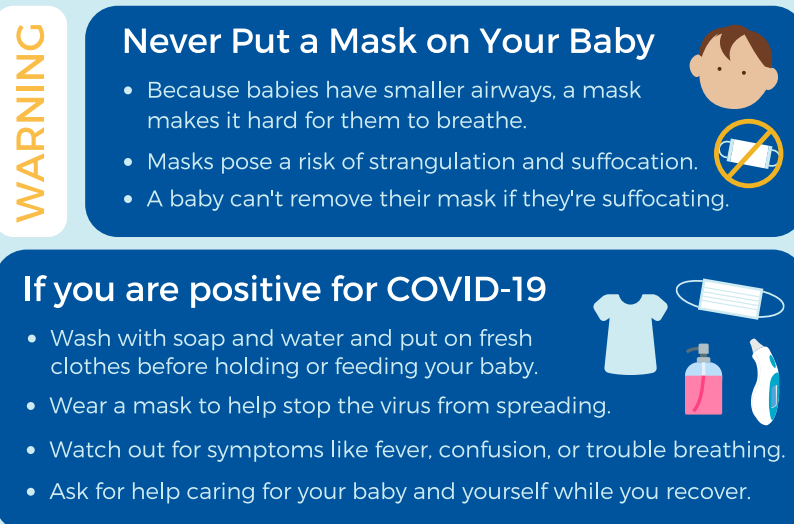

We can help protect each other.

Learn more

WWW.nationalperinatal.org/COVID-19

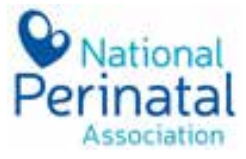

